\title{
Capacity and mechanism of phenol adsorption on lignite
}

\author{
H. Polat ${ }^{\mathrm{a}, *}$, M. Molva ${ }^{\mathrm{b}}$, M. Polat $^{\mathrm{c}}$ \\ a Department of Chemistry, Izmir Institute of Technology, Urla, Izmir, Turkey \\ b Environmental Engineering Program, Izmir Institute of Technology, Urla, Izmir, Turkey \\ ${ }^{\mathrm{c}}$ Department of Chemical Engineering, Izmir Institute of Technology, Urla, Izmir, Turkey
}

Received 26 January 2006; received in revised form 7 March 2006; accepted 7 March 2006

Available online 24 April 2006

\begin{abstract}
A raw lignitic coal from Soma, Turkey was investigated to determine its potential as an adsorbent for phenol removal from wastewaters. Kinetic batch tests demonstrated that phenol could be completely removed from solution given sufficient solids loading and reaction time. The adsorption capacity of $10 \mathrm{mg} / \mathrm{g}$ obtained with the lignite is low compared to those achievable with activated carbons (around $300 \mathrm{mg} / \mathrm{g}$ ). However, when normalized for the surface area, the adsorption capacity was much larger for the lignite $\left(1.3 \mathrm{mg} / \mathrm{m}^{2}\right)$ than that generally observed with activated carbons $\left(0.05-0.3 \mathrm{mg} / \mathrm{m}^{2}\right)$. Hydrogen-bonding of the phenolic $\mathrm{OH}$ with the oxygen sites on the lignite surface is the most likely mechanism for adsorption. Though water molecules also have affinity for the same oxygen sites, lateral benzene ring interactions make phenol adsorption energetically more favorable. Since phenol molecules adsorbed in this fashion would project their benzene rings into solution, formation of a second layer through the action of the dispersive $\pi-\pi$ interactions between the benzene rings is very likely. Residual water quality with respect to major elements and heavy metals was within acceptable limits defined by the ASTM standards. Dissolution of organic matter from the lignite was also observed to be negligible.
\end{abstract}

(C) 2006 Published by Elsevier B.V.

Keywords: adsorption; phenol; lignite; oxidation; hydrogen-bonding; wastewater

\section{Introduction}

Phenol and its derivatives are present in the wastewaters of such industries as petroleum refining, leather and textile manufacturing, olive oil manufacturing etc. in appreciable quantities (Table 1) (Cermola et al., 2004; Kent, 1992; Rengaraj et al., 2002). Phenolic compounds have low allowable limits $(0.5-1.0 \mathrm{mg} / \mathrm{l})$ due to their toxicity to human and aquatic life and must be removed

\footnotetext{
* Corresponding author. Tel.: +90 2327507531 ; fax: +90 232750 7509.

E-mail address: hurriyetpolat@iyte.edu.tr (H. Polat).
}

from wastewaters in environmentally acceptable ways. Despite the existence of several physicochemical and biological treatment techniques (solvent extraction, ionexchange by resins, chemical oxidation by ozone, aerobic or anaerobic biodegradation, etc.), adsorption on activated carbons is the most effective and frequently used technique for phenol removal (Davis and Cornxvell, 1991; Nathanson, 1997; Monahan, 1998; Tong et al., 1998; Tchobanoglous and Stensel, 2002; Dabrowski et al., 2005).

Activated carbon is an expensive commodity. In the United States its current average bulk price from the major producers is listed as $\$ 2.5$ per kilogram with a demand of about 180 thousand tons forecasted for 2006 
Table 1

Levels of phenol reported in industrial wastewaters (Cermola et al., 2004; Kent, 1992; Rengaraj et al., 2002)

\begin{tabular}{ll}
\hline Industrial source & Phenol conc., mg/l \\
\hline Petroleum refineries & $40-185$ \\
Petrochemical & $200-1220$ \\
Textile & $100-150$ \\
Leather & $4.4-5.5$ \\
Coke ovens (without dephenolization) & $600-3900$ \\
Coal conversion & $1700-7000$ \\
Ferrous industry & $5.6-9.1$ \\
Rubber industry & $3-10$ \\
Pulp and paper industry & 22 \\
Wood preserving industry & $50-953$ \\
Phenolic resin production & 1600 \\
Phenolic resin & $1270-1345$ \\
Fiberglass manufacturing & $40-2564$ \\
Paint manufacturing & 1.1 \\
\hline
\end{tabular}

(Kirschner, 2006). These numbers provide compelling enough reasons for the search for cheaper adsorbents. Bentonites (Banat et al., 2000), zeolites (Roostaei and Tezel, 2004; García et al., 1993), surfactant treated smectides (Shen, 2004) and montmorillenites (Jiang et al., 2002), chitin (Dursun and Kalayci, 2005), bagasse fly ash (Srivastava et al., 2006) and organic beet pulp (Dursun et al., 2005) are some possible candidates investigated. However, lower fractional removals and adsorption capacities obtained with these adsorbents raise questions with respect to their efficiency and regeneration.

Though lignite has been used to prepare activated carbons (Streat et al., 1995; Duggan and Allen, 1997; Finqueneisel et al., 1998a,b; Aksu and Yener, 2001; Dabrowski et al., 2005), literature is scant in any work where raw lignites were employed directly for phenol adsorption. ${ }^{1}$ However, as it will be discussed in the Results and Discussion sections in detail, the presence of surface oxygen sites on carbon surface has been reported to have a capacity for binding phenol. Lignitic coals contain an abundance of such functional groups in their structure. Also, their very low bulk price and abundance are the obvious advantages of the lignites as potential adsorbents. Use of lignites in raw form also means avoiding the expensive pyrolysis step necessary for activated carbon preparation. Furthermore, the spent lignite may not necessarily be subject to the costly regeneration or disposal requirements. It can be burned directly, preferably on-site where the phenolic waste is generated since most of the facilities which generate

\footnotetext{
${ }^{1}$ The work appeared in journals covered by ScienceDirect between 1970 and 2006 are implied.
}

phenolic wastewaters are big users of energy raw materials (Table 1).

In this study, feasibility of using a raw lignite sample for phenol removal from wastewater without any pretreatment procedures was investigated. The parameters tested were the solid/liquid $(\mathrm{S} / \mathrm{L})$ ratio, initial phenol concentration, reaction time and temperature. A mechanism which explains the adsorption of the phenol on the lignite surface is proposed.

\section{Materials}

The lignite sample was from Soma Region in Western Turkey. The particle size was reduced to nominal passing $500 \mu \mathrm{m}$ in a laboratory jaw crusherhammer mill-screen setup. Representative samples of $250 \mathrm{~g}$ were stored in plastic bags under positive argon pressure. The results of the proximate and ultimate analyses are given in Table 2 along with the surface area measurements. Quartz, staurolite and muscovite were detected in the lignite structure in the XRD studies.

The phenol (molecular weight of $94.1 \mathrm{~g} / \mathrm{mol}$ ) was obtained from the Merc Chemical Company. At $25^{\circ} \mathrm{C}$, it has a relatively low vapor pressure of $0.41 \mathrm{~mm} \mathrm{Hg}$ and solubility in water of $8.2 \%$ by weight. Phenol solutions were prepared daily by dissolving a known amount of phenol in water below the solubility limit and were stirred for 30 min prior to adsorption experiments.

Double distilled water, which was passed through a Barnstead Easypure UV-Compact ultrapure water system $(18.3 \Omega)$, was used to prepare the solutions. Glassware was cleaned with chromic acid with subsequent rinsing with distilled water.

\section{Methods}

The kinetic batch adsorption studies were carried out at a constant temperature of $25^{\circ} \mathrm{C}$ and at a natural $\mathrm{pH}$ of about 8 unless otherwise stated. In the tests where the

Table 2

Characteristic properties of the Soma lignite sample

\begin{tabular}{lllrll}
\hline Physical properties & & Oxides, \% & \multicolumn{2}{l}{$\begin{array}{l}\text { Elements, } \\
\mathrm{mg} / \mathrm{kg}\end{array}$} \\
\hline Ash, \% & 32 & $\mathrm{CaO}$ & 33.8 & $\mathrm{~Pb}$ & 420 \\
Volatile matter, \% & $16-35$ & $\mathrm{SiO}_{2}$ & 33.4 & $\mathrm{Cu}$ & 172 \\
Fixed carbon, \% & 11 & $\mathrm{Al}_{2} \mathrm{O}_{3}$ & 16.1 & $\mathrm{Ni}$ & 152 \\
Moisture, \% & 21 & $\mathrm{Fe}_{2} \mathrm{O}_{3}$ & 6.0 & $\mathrm{Zn}$ & 116 \\
BET surface area, $\mathrm{m}^{2} / \mathrm{g}$ & 4.79 & $\mathrm{MgO}^{2}$ & 6.1 & $\mathrm{Co}$ & 104 \\
Micropore surface area, $\mathrm{m}^{2} / \mathrm{g}$ & 7.7 & $\mathrm{SO}_{3}$ & 2.8 & $\mathrm{Cr}$ & 64 \\
Nominal particle size, $\mu \mathrm{m}$ & 250 & $\mathrm{Na}_{2} \mathrm{O}$ & 1.1 & $\mathrm{Sr}$ & 60 \\
Calorific value, $\mathrm{kcal} / \mathrm{kg}$ & 2200 & $\mathrm{~K}_{2} \mathrm{O}$ & 0.7 & $\mathrm{Cd}$ & 52 \\
\hline
\end{tabular}


effect of S/L ratio was investigated, the solution phenol concentration was kept constant at $100 \mathrm{mg} / \mathrm{l}$ while the lignite amount was varied between 1.25 and $40 \mathrm{~g}$. In another set of tests, the $\mathrm{S} / \mathrm{L}$ ratio was kept constant at 0.05 while the initial phenol concentration was varied between 100 and $1000 \mathrm{mg} / \mathrm{l}$. All adsorption tests were carried out in $250 \mathrm{ml}$ polyethylene bottles containing $100 \mathrm{ml}$ phenol solution on an IKA Labortech-KS125 digital shaker and a Memmert Model (Germany) water bath with temperature adjustment. Each bottle was used to obtain a single sample to ensure a constant $\mathrm{S} / \mathrm{L}$ ratio throughout the experiments and to prevent accumulative error. The sampling times were $0.08,0.33,1.5,3,6,24$, 48, 96 and $168 \mathrm{~h}$. The supernatant solutions were analyzed for phenol with a UV Spectrophotometer (UV-VIS 1208 from Shimadzu) at $270 \mathrm{~nm}$. To determine the residual water quality after adsorption for heavy metals and major elements which may have dissolved from the lignite sample, selected supernatant solutions were analyzed by an ICP (Varian, AES Axial Liberty Series 2). The FTIR spectra of the as-received and treated lignite samples were obtained in $\mathrm{KBr}$ using a Shimazdu FTIR-8601 PC spectrometer (Kyoto, Japan with a resolution of $1.5 \mathrm{~cm}^{-1}$. The surface area was determined by a Micromeritics ASAP 2010 volumetric adsorption device employing nitrogen at a temperature of $77 \mathrm{~K}$. The device uses internal algorithms which employ the BET and the BJH models to obtain the BET and micropore surface areas, respectively. A Soxhlet evaporator-condenser was employed to determine the maximum amounts of organics dissolvable from the lignite sample. Macherey Nagel type $(40 \times 40)$ filter papers and membrane filters of $0.45 \mu \mathrm{m}$ from Sartorius (Minisart RC 25) were used for solid-liquid separation.

An initial kinetic experiment was carried out up to $200 \mathrm{~h}$ using a $100 \mathrm{mg} / \mathrm{l}$ phenol solution in the absence of solids to assess the amount of phenol loss from the

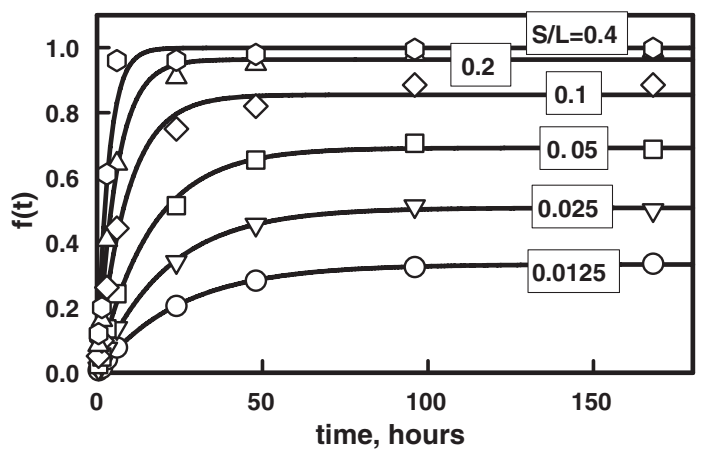

Fig. 1. Fractional phenol removals as a function of time for varying $\mathrm{S} / \mathrm{L}$ ratios $\left(f(t)=\left[C_{\mathrm{in}}-C_{\mathrm{res}}(t)\right] / C_{\mathrm{in}} ; C_{\mathrm{in}}=100 \mathrm{mg} / \mathrm{l} ; \mathrm{pH}=\right.$ natural $)$.

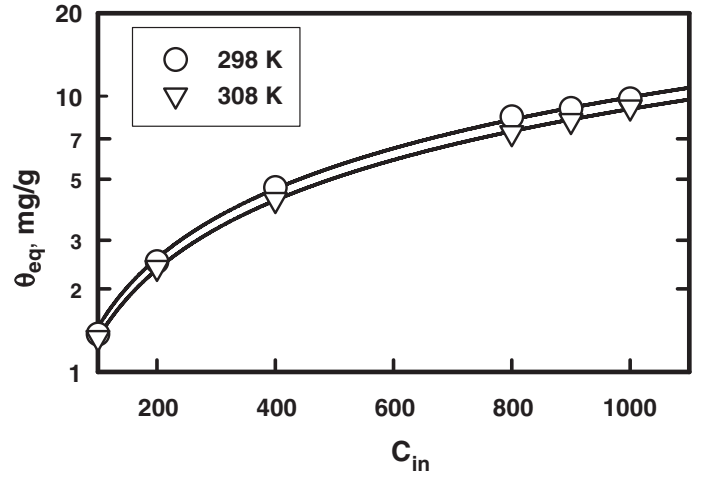

Fig. 2. Equilibrium adsorption capacities as a function of initial phenol concentration at two temperatures. $(\mathrm{S} / \mathrm{L}=0.05 ; \mathrm{pH}=$ natural $)$.

reaction bottles and to test the reproducibility of the analytical procedure. The residual phenol concentration at the conclusion of this test was $100 \pm 0.1 \mathrm{mg} / \mathrm{l}$, indicating excellent reproducibility and no significant phenol loss.

\section{Results}

Kinetic adsorption studies were carried out to determine the adsorption behavior of phenol on lignite at various $\mathrm{S} / \mathrm{L}$ ratios using an initial phenol concentration $\left(C_{\text {in }}\right)$ of $100 \mathrm{mg} / \mathrm{l}$. The results are presented in Fig. 1 in terms of fractional phenol removal from solution, $f(t)$, as a function of time where $f(t)=\left[C_{\text {in }}-C_{\text {res }}(t)\right] / C_{\text {in }}$. Here, $C_{\text {res }}(t)$ is the residual phenol concentration in solution at time $t$. The figure shows that fractional phenol removal increases with time and an equilibrium fractional phenol removal, $f_{\text {eq }}$, is approached for all $\mathrm{S} / \mathrm{L}$ ratios at long reaction times. It should be noted that as the $f_{\text {eq }}$ value increases towards 1.0 with increasing $\mathrm{S} / \mathrm{L}$ ratio. This demonstrates that it is possible to remove phenol completely when there is sufficient lignite surface area in solution. According to the figure, the $\mathrm{S} / \mathrm{L}$ ratios over 0.2 provide complete removal of phenol.

Fig. 2 presents the equilibrium adsorption capacities $\left(\theta_{\text {eq }}, \mathrm{mg}\right.$ phenol adsorbed on each gram of lignite at extended times) as a function of initial phenol concentration for two different temperatures. In these tests, the $\mathrm{S} / \mathrm{L}$ ratio was kept constant at 0.05 while the initial phenol concentration was varied between 100 and $1000 \mathrm{mg} / \mathrm{l}$. It can be seen that adsorption capacity increases significantly with increasing initial concentration, but tapes off towards a seemingly limiting value of about $10 \mathrm{mg} / \mathrm{g}$. Though the effect of temperature is negligible at low initial phenol concentrations, the adsorption capacity becomes slightly lower at high initial phenol concentrations for the higher temperature. 
The adsorption capacity of $10 \mathrm{mg} / \mathrm{g}$ is low when compared to the usual adsorption capacities observed with activated carbons $(100-300 \mathrm{mg} / \mathrm{g})$. This is most probably due to the small surface area of the lignite sample $\left(7.7 \mathrm{~m}^{2} / \mathrm{g}\right)$ compared to those usually associate with activated carbons (in the order of $1000 \mathrm{~m}^{2} / \mathrm{g}$ ).

Fig. 3 gives the adsorption capacities obtained at different temperatures $\left(25,30,35\right.$, and $\left.40{ }^{\circ} \mathrm{C}\right)$ as a function of time. The figure shows that the equilibrium adsorption capacity demonstrates a slight but steady decrease with increasing temperature; $\theta_{\text {eq }}$ decreasing from 1.41 to $1.22 \mathrm{mg} / \mathrm{g}$ with an increase in temperature from 25 to $40{ }^{\circ} \mathrm{C}$. The solid lines in the figure were drawn using a first-order rate equation in the form:

$\theta(t)=\theta_{\mathrm{eq}}\left(1-e^{-k t}\right)$

where $k$ is the apparent reaction constant. It can be seen that the agreement between the first-order equation and the kinetic data is very satisfactory.

Among the empirical models tested (Freundlich, Langmuir and BET), the Freundlich isotherm was observed with the adsorption data obtained. This isotherm, which is known to better represent heterogeneous adsorbent and multilayer adsorption cases (Brev, 1958), can be expressed in the form:

$\theta_{\text {eq }}=k_{\mathrm{F}} C_{\mathrm{eq}}^{n}$

In this above equation, $C_{\mathrm{eq}}$ is the equilibrium residual phenol concentration. The parameter $k_{\mathrm{F}}$ is the empirical Freundlich constant related to adsorption capacity $n$ is the Freundlich exponent related to the strength of adsorption. A comparison of the experimental data with the Freundlich isotherm is shown in Fig. 4 for 298 and $308 \mathrm{~K}$. The estimates of the model parameters,

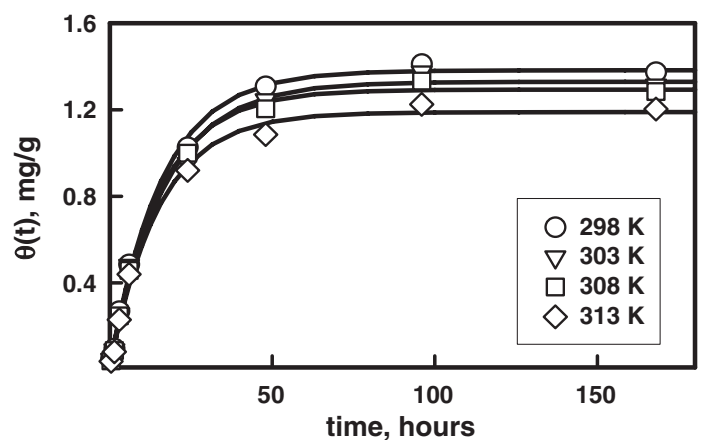

Fig. 3. Effect of temperature on adsorption of phenol on the lignite. The solid lines are predicted by the equation $\theta(t)=\theta_{\mathrm{eq}}\left(1-e^{-k_{2} t}\right)$ $\left(C_{\text {in }}=100 \mathrm{mg} / \mathrm{l} ; \mathrm{S} / \mathrm{L}=0.05 ; \mathrm{pH}=\right.$ natural $)$.

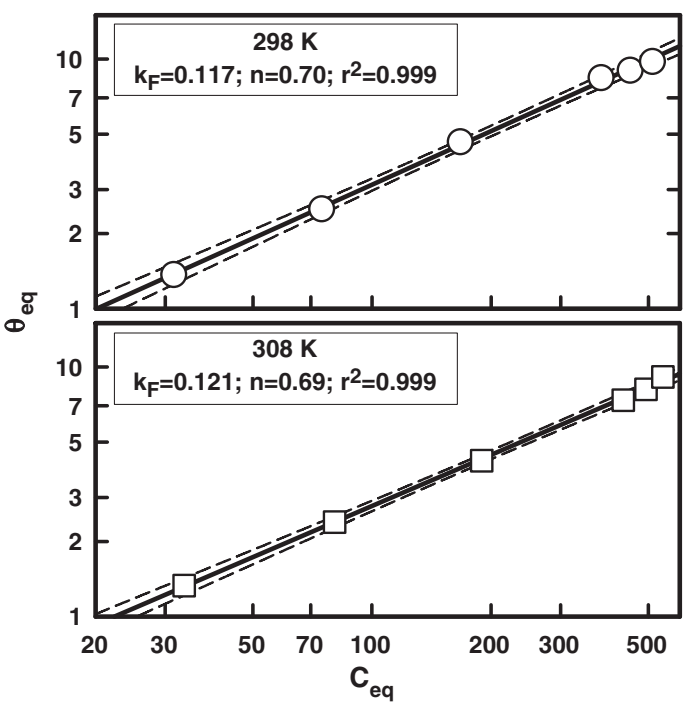

Fig. 4. Application of the Freundlich isotherm to the adsorption data at two temperatures. The solid lines are the best-fit lines which give the parameter estimates in the inset boxes and the broken lines show the $99 \%$ confidence intervals $(\mathrm{S} / \mathrm{L}=0.05 ; \mathrm{pH}=$ natural $)$.

goodness of fit and $95 \%$ confidence intervals are also presented in the figure. The magnitudes of the model parameters are rather small and remain nearly constant with the change in temperature $\left(k_{\mathrm{F}} \cong 0.119\right.$ and $\left.n \cong 0.70\right)$. Such small values are indicative of a relatively low adsorption capacity and weak bonding (Schwarzenbach et al., 2003). As a comparison, a commercial activated carbon (Filtrasorb 300, Calgon Corporation) has $k_{\mathrm{F}}$ value of 21 and $n$ value of 1.85 (Dabrowski et al., 2005 after Dobbs and Cohen, 1980).

Fig. 3 demonstrated that the change in the adsorption capacity with time can be represented quite well by a first-order rate equation. In Fig. 5, the apparent reaction constants for the four temperatures obtained from Fig. 3

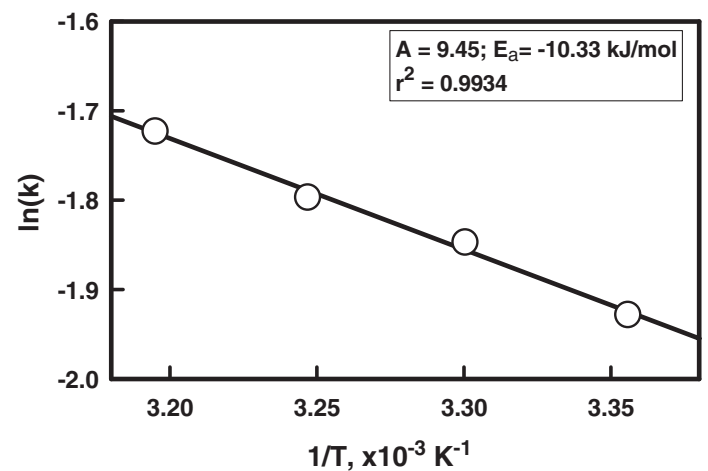

Fig. 5. The $\ln (k)$ versus $1 / T$ plot to calculate the activation energy, $E_{\mathrm{a}}$, from the data given in Fig. 3. 
are plotted in the form of an $\ln (k)$ vs. $1 / T$ plot. According to the Arrhenius Equation, the slope of the line in Fig. 5 should give the activation energy, $E_{\mathrm{a}}$ since

$\ln (k)=\ln A-\frac{E_{\mathrm{a}}}{R T}$

The magnitude of $E_{\mathrm{a}}$ comes out to be $10.3 \mathrm{~kJ} / \mathrm{mol}$ from the figure. The low value of $E_{\mathrm{a}}$ also implies weak bonding between phenol and the lignite (Atkins, 1994; Yin et al., 2002).

The heat of adsorption, $\Delta H$, which gives the change in the enthalpy of the system upon adsorption can be calculated using the Van't Hoff Equation:

$\Delta H=\frac{R T_{1} T_{2} \ln \left(K_{\mathrm{d} 1} / K_{\mathrm{d} 2}\right)}{T_{2}-T_{1}}$

where $K_{\mathrm{d} 1}$ and $K_{\mathrm{d} 1}$ are the distribution constants at $T_{1}$ and $T_{2}$. The distribution constant $K_{\mathrm{d}}$ is equal to the ratio of the equilibrium concentrations of phenol adsorbed on lignite and remaining in solution at a given temperature. The heat of adsorption values as a function of initial phenol concentration in solution are given in Fig. 6. It can be seen that $\Delta H$ values are negative for all initial concentrations studied, indicating an exothermic reaction. Also, the absolute magnitude of $\Delta H$ is always lower than $20 \mathrm{~kJ} / \mathrm{mol}$. An adsorption process is generally considered physical if $\Delta H<25 \mathrm{~kJ} / \mathrm{mol}$ and chemical when $\Delta H>40 \mathrm{~kJ} / \mathrm{mol}$.

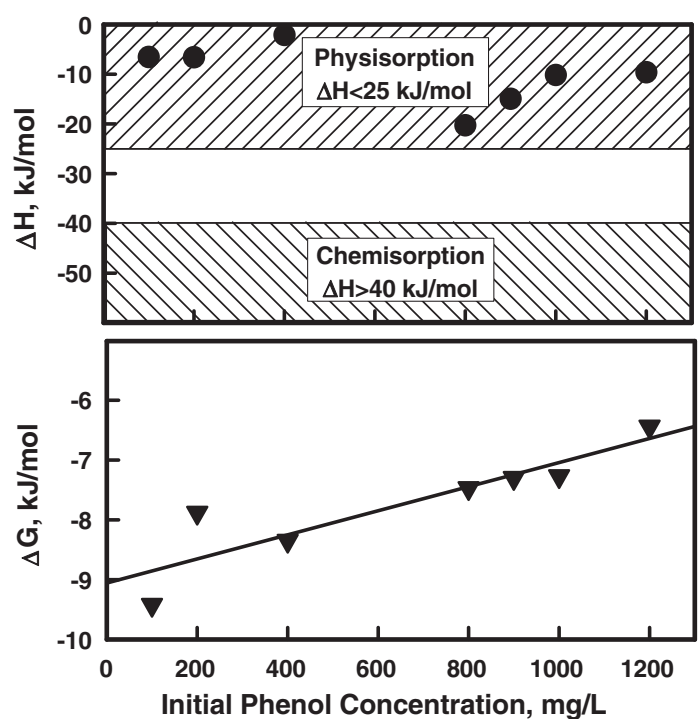

Fig. 6. Heats of adsorption and Gibbs free energies for the adsorption of phenol on the lignite as a function of initial phenol concentration.

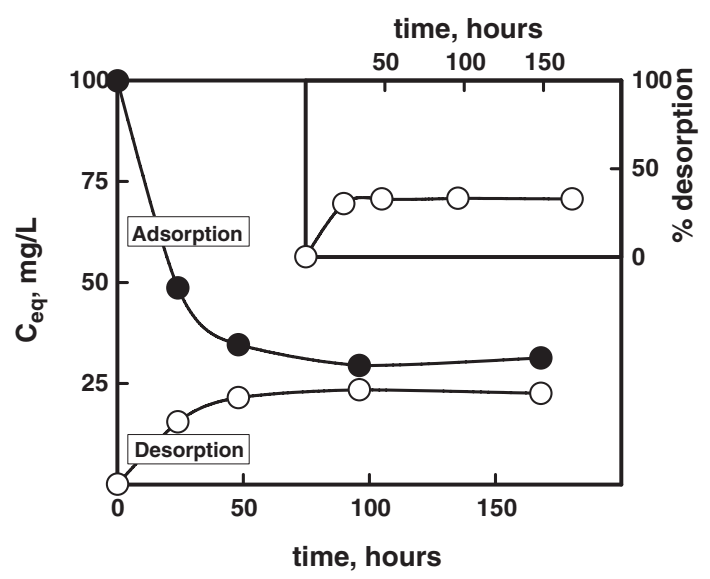

Fig. 7. Adsorption and desorption of phenol from the lignite sample after washing with water $\left(C_{\mathrm{in}}=100 \mathrm{mg} / \mathrm{l}, \mathrm{S} / \mathrm{L}=0.05, \mathrm{pH}=\right.$ natural $)$.

Fig. 6 presents the average Gibbs free energies for the two temperatures calculated using the equation:

$\Delta G=-R T \ln \left(K_{\mathrm{d}}\right)$

The negative $\Delta G$ values in the figure indicate spontaneous adsorption of the phenol molecules on the lignite surface. It should be noted that the absolute magnitudes of the Gibbs free energies are larger for low initial concentrations (around to $10 \mathrm{~kJ} / \mathrm{mol}$ ) where the monolayer coverage is more likely and show a small but a progressive decrease with increasing initial phenol concentration.

A desorption test using only distilled water to wash the phenol from the lignite surface was also carried out to determine the fraction of weakly-bonded phenol (Fig. 7). The figure shows that about $33 \%$ of the phenol can be removed from the surface with water-washing alone, indicating that a significant fraction of the phenol is very weakly adsorbed.

The water quality with respect to heavy metals and major elements dissolvable from the lignite sample was determined using the Standard Method ASTM D-4793 (ASTM, 1995). The result was presented in Fig. 8. It can be seen there is no significant dissolution of heavy metals. For those heavy metals which show a certain amount of dissolution, the observed values were always below the limiting values set by the Environmental Regulations for Water Quality (Classes I, II, III and IV). Also, a Soxhlet evaporator-condenser set-up was used to determine the maximum amount of dissolvable organics material from the lignite sample. In this test, the lignite sample was repeatedly washed by evaporating, condensing and percolating the same water through the lignite sample until no significant changes in solution 


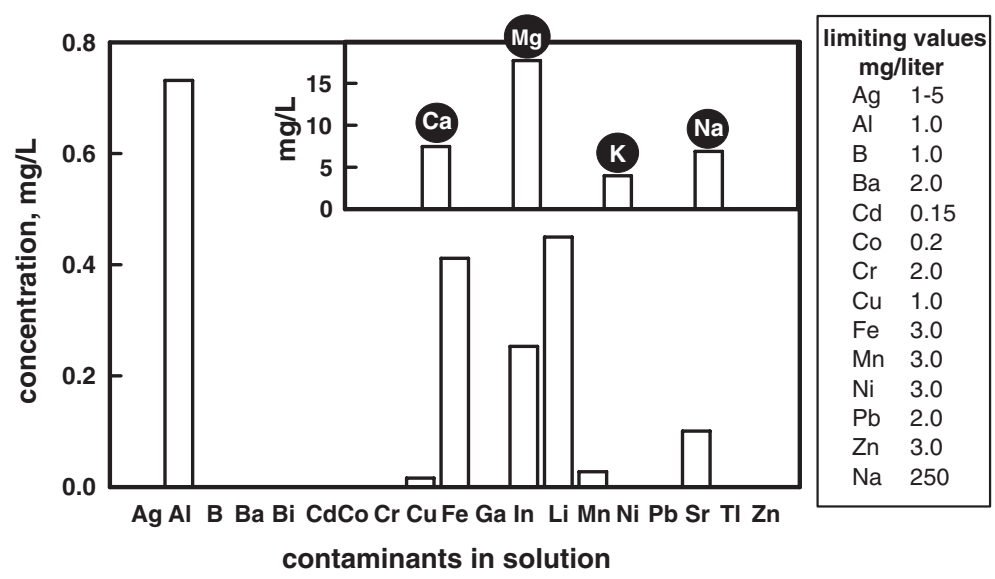

Fig. 8. Dissolution of the major and trace elements from the lignite sample determined by the ASTM analysis. The metals which do not display a visible bar are below detection limits. Limiting values set by the Environmental Regulations for wastewater are shown in the side bar.

composition could be observed. The total amount dissolved material was found to be $1.57 \mathrm{mg}$ for $1 \mathrm{~g}$ of lignite. Out of this amount, $0.76 \mathrm{mg}$ was determined to be comprised of $\mathrm{Ca}, \mathrm{Mg}, \mathrm{Na}$ and $\mathrm{K}$. Hence, the maximum amount of organic matter dissolved from the lignite sample, most probably in the form of humic species, was about $0.81 \mathrm{mg}$ for each gram of lignite.

\section{Discussion}

The adsorption studies carried out at different $\mathrm{S} / \mathrm{L}$ ratios at a solution phenol concentration of $100 \mathrm{mg} / \mathrm{l}$, which is usually encountered in wastewaters (see Table 1), show that the lignite sample is capable of removing the phenol completely from solution at $\mathrm{S} / \mathrm{L}$ ratios of 0.2 and above (Fig. 1). The studies at a constant $\mathrm{S} / \mathrm{L}$ ratio and at varying initial phenol concentration, on the other hand, demonstrate that adsorption capacities as high as $10 \mathrm{mg} / \mathrm{g}$ can be obtained with the lignite sample (Fig. 2). Further work, preferably in pilot scale, is needed to determine the optimum conditions both with respect to the efficiency of removal and the efficiency of adsorption capacity.

The phenol adsorption capacity observed with the lignite is an order of magnitude lower than the adsorption capacities usually observed with activated carbons, which range between 50 and $300 \mathrm{mg} / \mathrm{g}$ (Coughlin et al., 1968; Franz et al., 2000; Zawadski, 1988; Terzyk, 2004; Dabrowski et al., 2005). Such high values are due the enormous surface area of activated carbons. The micropore surface area is usually in the order of $1000 \mathrm{~m}^{2} / \mathrm{g}$ for the activated carbons whereas it was only $7.7 \mathrm{~m}^{2} / \mathrm{g}$ for the lignite sample. Therefore, when expressed in terms of per unit surface area, lignite seems to give a surprisingly good adsorption capacity.
The adsorption capacity per unit area comes out to be around $1.3 \mathrm{mg} / \mathrm{m}^{2}$ for the lignite sample as opposed to the typically observed values of $0.05-0.3 \mathrm{mg} / \mathrm{m}^{2}$ for activated carbons.

These observations necessarily point out to two conclusions: First, it is apparent that the fraction of the surface area contributing to adsorption is orders of magnitude higher for the lignite. This is in fact not quite surprising since approximately $80 \%$ of the micropore pore volume in activated carbons belong to the pores with diameters less than about $8 \AA$ (Franz et al., 2000; Terzyk, 2003, 2004; Gauden et al., 2004). The diameter of an unhydrated phenol molecule has been to be about $6.0 \AA$ both experimentally (Singh et al., 1996) and computer simulations (Mooney et al., 1998). Since a phenol molecule must pass by another to diffuse into the pores, it is obvious that a vast amount of activated carbon surface would be inaccessible for phenol. On the contrary, small angle neutron scattering studies indicate that coals in general have negligible micropore structure (Yamada, 1996). In the case of lignites, Polat et al. (1996) observed during controlled oxidation studies that the majority of the surface area is due to the macrocracks which are directly accessible from the external surface as have been observed.

The second conclusion arising from the observed adsorption densities is that the phenol molecules must be adsorbing quite generously on the lignite surface. Different parking areas have been reported for phenol depending on its orientation on the surface; $45 \AA^{2}$ (Mattson et al., 1969) and 52.2 $\AA^{2}$ (Puri et al., 1975) for planar orientation and $28 \AA^{2}$ for edge-on and $24.8 \AA^{2}$ for end-on orientations (Singh, 1971; MacDonald and Evans, 2002). McClellan and Harnsberger (1967) give phenol parking area as $30.5 \AA^{2}$ based on adsorption 
tests. Planar and end-on orientations on the surface necessarily means that phenol adsorbs through the benzene ring whereas an edge-on orientation involves bonding through the $-\mathrm{OH}$ functionality. Assuming an edge-on orientation for reasons which will be apparent in the following paragraphs, the adsorption density of $10 \mathrm{mg} / \mathrm{g}$ (Fig. 2) would require a surface area of approximately $18 \mathrm{~m}^{2}$. Since the lignite sample has a surface area of $7.7 \mathrm{~m}^{2}$ per gram, it is obvious that phenol must also be adsorbing in secondary layers.

There is a voluminous amount of work on the adsorption mechanism of aromatic compounds, specifically phenol, on carbon material. A comprehensive review of this literature can be found in papers by Radovic et al. (2000), Terzyk (2004) and Dabrowski et al. (2005). It is generally accepted that aromatic compounds adsorb on the unoxidized graphitic part of the surface physically through dispersive interactions between the $\pi$-electrons of the graphitic carbon basal planes and those of the phenol aromatic ring (Coughlin and Ezra, 1968). However, although carbon surface also contain oxygen-rich sites (mainly in the form of basic carbonyl- $\mathrm{COH}$, acidic carboxyl- $\mathrm{COOH}$ and phenolic hydroxyl-OH functionalities), the influence of these groups on phenol adsorption has not been resolved. Mattson et al. (1969) propose a donor-acceptor complex formation between the negatively charged aromatic ring and the positively charged basal plane for phenol adsorption on oxygen sites though the importance of such complex formation has been seriously questioned in more recent work (Franz et al., 2000; Terzyk, 2004).

Another more likely mechanism for phenol adsorption on oxidized sites is hydrogen-bonding since the phenolic $-\mathrm{OH}$ has been shown to be capable of such bonding (Guedes et al., 2003). Such adsorption implies that oxidation of the carbon surface should promote adsorption capacity. However, several works report a decrease in phenol adsorption from water with surface oxidation (Coughlin and Ezra, 1968; Coughlin et al., 1968; Mahajan et al., 1980; Leng, 1996; Franz et al., 2000; Terzyk, 2003, 2004; Moreno-Castilla, 2004). Since lignites are rich in oxygen surface groups (Yaman et al., 2000; Küçükbayrak et al., 2000), they have a high affinity for water (Allardice and Evans, 1971; Schafer, 1972; Kaji et al., 1986; Müller and Gubbins, 1998; Lee and Reucroft, 1999). Therefore, the decrease in adsorption with oxidation is attributed to the preferential hydration of the surface oxygen groups over the hydrogen-bonding of the $-\mathrm{OH}$ of the phenol molecule. However, studies which demonstrate enhanced phenol adsorption from aqueous solutions with surface oxida- tion also exist in the literature (Zawadski, 1988; Finqueneisel et al., 1998a,b; Tessmer et al., 1997).

Since hydrogen-bonding is an extremely fast dynamic process with a time scale of around $0.2 \mathrm{ps}$ (Asbury et al., 2004), an enormous number of bond formation and breaking must be taking place in solution at a given instant. Though water is usually cited for its polarity due to its high dipole moment (1.85 Debye), the phenol molecule is also strongly polarized (1.61 Debye). Such high polarity implies that the phenol molecules must also be forming momentary hydrogen bonds with the surface oxygen groups. While the number of phenolic bonds maybe smaller on the average compared to the those formed by water, the lateral dispersive interactions of the benzene rings of the adsorbed phenol molecules should also be taken into account. Dispersive attraction between two benzene rings is twice as large as those between two water molecules and four times as large as those between a water molecule and a benzene molecule at a given separation (Polat and Polat, 2000). Removal of a phenol molecule adsorbed next to another will require an additional energy for overcoming the benzene ring interactions. Hence, such strong lateral interactions would lead to a cumulative effect in favor of phenol adsorption, those molecules on the surface acting as nucleation sites for further adsorption. Adsorbed in this fashion, phenol molecules will be projecting their benzene rings towards the water. Such orientation may lead to the development of a secondary layer through the benzene ring interactions.

The small values of the Freundlich parameter $(n \cong 0.7)$ in Fig. 4 indicate physical adsorption. The small activation energy in Fig. $5(10.3 \mathrm{~kJ} / \mathrm{mol})$ and heat of adsorption values in Fig. 6 (between -6 and $-20 \mathrm{~kJ} /$ mol) support the proposed mechanism. The negative Gibbs free energies in Fig. 6 demonstrate that adsorption of phenol is spontaneous. The Gibbs free energy of $-10 \mathrm{~kJ} / \mathrm{mol}$ at the low initial concentration range where monolayer adsorption should be dominant probably represents hydrogen-bonding energy of phenol onto the surface oxygen. The energy decreases towards $-6 \mathrm{~kJ} /$ mol with increasing initial phenol concentration, implying that adsorption of phenol molecules as a second layer through the benzene ring interactions was less energetic. This is not surprising since the hydrogenbonding energies related to the formation of the first layer must be higher than the dispersive $\pi-\pi$ interaction energies which bind the second layer.

Finally, the FTIR spectra of phenol presents $\mathrm{H}$ bonded $-\mathrm{OH}$ stretch at $3600-3100 \mathrm{~cm}^{-1}$ and $\mathrm{C}-\mathrm{O}$ stretch at $1300-1100 \mathrm{~cm}^{-1}$. It also present aromatic ring absorptions of $=\mathrm{C}-\mathrm{H}$ at $3100-3000 \mathrm{~cm}^{-1}$ and $\mathrm{C}-\mathrm{C}$ at 
$1600 \mathrm{~cm}^{-1}$ and $1500-1450 \mathrm{~cm}^{-1}$ (FDM, 2002). On the other hand, the lignite sample used in this work also generated these bands very broadly due to the abundance of surface oxygen groups. Therefore, the FTIR spectra of the as-received lignite sample and the lignite samples treated in water and in phenol solutions yielded no discernible differences and are not reported here.

\section{Conclusions}

Batch studies were carried out to investigate the capacity and mechanism of phenol adsorption on lignite as a function of $\mathrm{S} / \mathrm{L}$ ratio, initial concentration and temperature. The specific conclusions based on the findings of this study are as follows:

1. Complete removal of phenol from water was possible using the raw lignite as an adsorbent. Fractional removal values of $100 \%$ could be obtained for an initial phenol concentration of $100 \mathrm{mg} / \mathrm{l}$ at $\mathrm{S} / \mathrm{L}$ ratios of 0.2 and higher.

2. Despite the low adsorption capacities per gram of adsorbent (about a tenth of those obtained with activated carbons), the adsorption capacity per unit adsorbent surface area was much larger (at least four times of those obtained with activated carbons). This illustrates that phenol adsorbs generously on the lignite surface and the relatively low adsorption capacity is due to the smaller surface area of the lignite.

3. The primary mode of adsorption is proposed to be the hydrogen-bonding of the $-\mathrm{OH}$ group on the phenol molecule onto the polar oxygen sites on the lignite surface. The relatively small difference between the polarities of the phenol and water molecules aided by lateral interactions between the benzene rings of the adsorbed phenol molecules makes such bonding energetically more favorable compared to the hydrogen-bonding of the water molecules to the same oxygen sites.

4. A comparison of the adsorbed amounts and the available lignite surface area implies that phenol produces a second layer on the lignite surface. Since the primary layer phenol molecules on the lignite would be projecting their benzene rings into solution, the benzene ring interactions between the adsorbed phenol molecules and those in the solution are likely to be the mechanism for the formation of the secondary layer.

5. The results obtained in this work (negligible negative changes in adsorbed amounts with changes in temperature, small Freundlich parameters, activation, heat of adsorption and Gibbs free energies which are all below $20 \mathrm{~kJ} / \mathrm{mol}$ ) show that adsorption of phenol on lignite falls in the physisorption category and support the mechanism described.

6. Water quality tests carried out using the ASTM procedure demonstrated that the effluent quality following adsorption was within environmental standards. The concentration levels of major elements and heavy metals were well under the defined standard levels for wastewater. The amount of organic matter dissolved from the lignite was also negligible.

The above conclusions suggest that raw lignites, which are inexpensive and abundant raw materials throughout the world, are viable candidates for the treatment of phenolic wastewaters. Use of raw lignites as adsorbent in this fashion by-passes the expensive pyrolysis procedures for surface activation. Moreover, the spent adsorbent may be directly utilized on-site as an energy source where the phenolic wastewater is generated. Such possibility means avoiding the necessary regeneration or disposal requirements for other adsorbents.

\section{References}

Aksu, Z., Yener, J., 2001. A comparative adsorption/biosorption study of mono-chlorinated phenols onto various sorbents. Waste Management 21, 695-702.

Allardice, D.J., Evans, D.G., 1971. The brown coal/water system: Part 2. Water sorption isotherms on bed-moist Yallourn brown coal. Fuel 50, 236-253.

Asbury, J.B., Steinel, T., Fayer, M.D., 2004. Hydrogen Bond Networks: Structure and Evolution after Hydrogen Bond Breaking. Journal of Physical Chemistry. B 108, 6544-6554.

ASTM, 1995. Annual Book of ASTM Standards, 11.04, p. 58.

Atkins, P.V., 1994. Physical Chemistry, 5th edition. Oxford University Press, p. 577.

Banat, F.A., Al-Bashir, B., Al-Asheh, S., Hayajneh, O., 2000. Adsorption of phenol by bentonite. Environmental Pollution 107, 391-398.

Brev, W.S., 1958. Principles of Physical Chemistry. Appleton-CenturyCrafts Inc., p. 20.

Cermola, F., DellaGreca, M., Iesce, R., Montella, S., Pollio, A., Temussi, F., 2004. A mild photochemical approach to the degradation of phenols from olive oil mill wastewater. Chemosphere 55, 1035-1041.

Coughlin, R.W., Ezra, F.S., 1968. Role of surface acidity in the adsorption of organic pollutants on the surface of carbon. Environmental Science and Technology 2, 291-297.

Coughlin, R.W., Ezra, F.S., Tan, R.N., 1968. Influence of chemisorbed oxygen in adsorption onto carbon from aqueous solution. Journal of Colloid and Interface Science 26, 386-396.

Dabrowski, A., Podkoscielny, P., Hubicki, Z., Barczak, M., 2005. Adsorption of phenolic compounds by activated carbon - a critical review. Chemosphere 58, 1049-1070. 
Davis, L.M., Cornxvell, D.A., 1991. Introduction to Environmental Engineering. Mc. Graw Hill International, p. 676.

Dobbs, R.A., Cohen, J.M., 1980. Carbon Adsorption Isotherm of Toxic Organics, EPA-600/8-80-023, V.S. Environmental Protection Agency.

Duggan, O., Allen, S.J., 1997. Study of the physical and chemical characteristics of a range of chemically treated, lignite based carbons. Water Science and Technology 35, 21-27.

Dursun, A.Y., Kalayci, C.S., 2005. Equilibrium, kinetic and thermodynamic studies on the adsorption of phenol onto chitin. Journal of Hazardous Materials 123, 151-157.

Dursun, G., Cicek, H., Dursun, A.Y., 2005. Adsorption of phenol from aqueous solution by using carbonized beet pulp. Journal of Hazardous Materials 125, 175-182.

FDM Electronic Handbook, 2002. Version 1.70, Fiveash Data Management Inc., WI, USA.

Finqueneisel, G., Zimny, T., Albiniak, A., Siemieniewska, T., Vogt, D., Weber, J.V., 1998a. Cheap adsorbent. Part 1: active cokes from lignites and improvement of their adsorptive properties by mild oxidation. Fuel 77, 549-556.

Finqueneisel, G., Zimny, T., Vogt, D., Weber, J.V., 1998b. Feasibility of the preparation of effective cheap adsorbents from lignites in rotary kiln. Fuel Processing Technology 57, 195-208.

Franz, M., Arafat, H.A., Pinto, N.G., 2000. Effect of chemical surface heterogeneity on the adsorption mechanism of dissolved aromatics on activated carbon. Carbon 38, 1807-1819.

García, J.E., González, M.M., Notario, J.S., 1993. Phenol adsorption on natural phillipsite. Reactive Polymers 21, 171-176.

Gauden, P.A., Terzyk, A.P., Rychlicki, G., Kowalczyk, P., Cwiertnia, M.S., Jerzy, K., Garbacz, J.K., 2004. Estimating the pore size distribution of activated carbons from adsorption data of different adsorbates by various methods. Journal of Colloid and Interface Science 273, 39-63.

Guedes, R.C., Coutinho, K., Costa Cabral, B.J., Canuto, S., 2003. Differential hydration of phenol and phenoxy radical and the energetics of the phenol $\mathrm{O}-\mathrm{H}$ bond in solution. Journal of Physical Chemistry. B 107, 4304-4310.

Jiang, J.Q., Cooper, C., Ouki, S., 2002. Comparison of modified montmorillonite adsorbents: Part I: preparation, characterization and phenol adsorption. Chemosphere 47, 711-716.

Kaji, R., Muranaka, Y., Otsuka, K., Hishinuma, Y., 1986. Water adsorption by coals: effect of pore structure and surface oxygen. Fuel 65, 288-291.

Kent, J.A., 1992. Riegel's Handbook of Industrial Chemistry, 9th edition. Van Nostrand Reinhold Publications, p. 50.

Kirschner, M., 2006. Contact Person, Innovation Group, 26 Fairmount Avenue. Morristown, NJ 07960, USA. WEB page: http://www.theinnovation-group.com/contact.htm.

Küçükbayrak, S., Haykırı-Açma, H., Ersoy-Meriçboyu, A., Yaman, S., 2000. Effect of lignite properties on reactivity of lignite. Energy Conversion and Management 42, 613-626.

Lee, W.H., Reucroft, P.J., 1999. Vapor adsorption on coal- and woodbased chemically activated carbons: (I) surface oxidation states and adsorption of $\mathrm{H}_{2} \mathrm{O}$. Carbon 37, 7-14.

Leng, C.C., 1996. Mechanism of adsorption and desorption of oxygen and nitrogen containing aromatics on activated carbon. $\mathrm{PhD}$ Thesis, University of Cincinnati, OH, USA.

MacDonald, J.A.F., Evans, M.J.B., 2002. Adsorption and enthalpy of phenol on BPL carbon. Carbon 40, 703-707.

Mahajan, O.P., Moreno-Castilla, C., Walker Jr., P.L., 1980. Surfacetreated activated carbon for removal of phenol from water. Separation Science and Technology 15, 1733-1752.
Mattson, J.S., Mark Jr., H.B., Malbin, M.D., Weber Jr., W.J., Crittenden, J.C., 1969. Surface chemistry of activated carbon: specific adsorption of phenols. Journal of Colloid and Interface Science 31, 116-130.

McClellan, A.L., Harnsberger, H.F., 1967. Cross-sectional areas of molecules adsorbed on solid surfaces. Journal of Colloid and Interface Science 23, 577-599.

Monahan, E.S., 1998. Environmental Chemistry. Lewis Publisher Press, p. 241.

Mooney, D.A., Müller-Plathe, F., Kremer, K., 1998. Simulation studies for liquid phenol: properties evaluated and tested over a range of temperatures. Chemical Physics Letters 294, 135-142.

Moreno-Castilla, C., 2004. Adsorption of organic molecules from aqueous solutions on carbon materials. Carbon 42, 83-94.

Müller, E.A., Gubbins, K.E., 1998. Molecular simulation study of hydrophilic and hydrophobic behavior of activated carbon surfaces. Carbon 36, 1433-1438.

Nathanson, A.J., 1997. Basic Environmental Technology: Water Supply Waste Management and Pollution Control. Prentice Hall, p. 314.

Polat, M., Polat, H., 2000. A review of the theory of interactions between particles dispersed in aqueous media, II. Van der Waals interactions. Journal of Ore Dressing 3, 21.

Polat, H., Polat, M., Chander, S., Hogg, R., 1996. The electrostatic charge on particles and its relation to agglomeration in air. Journal of Applied Occupational and Environmental Hygiene 11, 817.

Puri, B.R., Bhardwaj, S.S., Kumar, V., Mahajan, O.P., 1975. Adsorption of phenol from aqueous solution by carbons as influenced by surface oxygen complexes. Journal of Indian Chemical Society LII, 26-29.

Radovic, L.R., Moreno-Castilla, C., Rivera-Utrilla, J., 2000. Carbon materials as adsorbents in aqueous solutions. Chemistry and Physics of Carbon, vol. 27. Marcel Dekker, New York, pp. 227-405.

Rengaraj, S., Moon, S.H., Sivabalan, R., Arabindoo, B., Murugesan, V., 2002. Agricultural solid waste for the removal of organics: adsorption of phenol from water and wastewater by palm seed coat activated carbon. Waste Management 22, 543-548.

Roostaei, N., Tezel, F.H., 2004. Removal of phenol from aqueous solutions by adsorption. Journal of Environmental Management $70,157-164$.

Schafer, H.N.S., 1972. Factors affecting the equilibrium moisture contents of low-rank coals. Fuel 51, 4-9.

Schwarzenbach, R.P., Gschwend, M.P., Imboden, D.M., 2003. Environmental Organic Chemistry. John Wiley \& Sons, Inc., p. 278.

Shen, Y.H., 2004. Phenol sorption by organoclays having different charge characteristics. Colloids and Surfaces. A, Physicochemical and Engineering Aspects 232, 143-149.

Singh, D.D., 1971. Surface orientation of phenol molecules adsorbed from aqueous solution by carbon blacks. Indian Journal of Chemistry 9, 1369-1371.

Singh, B., Madhusudhanan, S., Dubey, V., Nath, R., Rao, N.B.S.N., 1996. Activated carbon for removal of toxic chemicals from contaminated water. Carbon 34, 327-330.

Srivastava, V.C., Swamy, M.M., Mall, I.D., Prasad, B., Mishra, I.M., 2006. Adsorptive removal of phenol by bagasse fly ash and activated carbon: equilibrium, kinetics and thermodynamics. Colloids and Surfaces. A, Physicochemical and Engineering Aspects 272, 89-104.

Streat, M., Patrick, J.W., Camporro Perez, M.J., 1995. Sorption of phenol and para-chlorophenol from water using conventional and novel activated carbons. Water Resources 29, 467-472. 
Tchobanoglous, G., Stensel, H.D., 2002. Metcalf and EddyWastewater Engineering: Treatment and Reuse, 4th ed. Mc Graw Hill International.

Terzyk, A.P., 2003. Further insights into the role of carbon surface functionalities in the mechanism of phenol adsorption. Journal of Colloid and Interface Science 268, 301-329.

Terzyk, A.P., 2004. Molecular properties and intermolecular forcesfactors balancing the effect of carbon surface chemistry in adsorption of organics from dilute aqueous solutions. Journal of Colloid and Interface Science 275, 9-29.

Tessmer, C.H., Vidic, R.D., Uranowski, L.J., 1997. Impact of oxygencontaining surface functional groups on activated carbon adsorption of phenols. Environmental Science and Technology 31, $1872-1878$.
Tong, Z., Qingxiang, Z., Hui, H., Qin, L., Yi, Z., Min, Q., 1998. Kinetic study on the removal of toxic phenol and chlorophenol from waste water by horseradish peroxidase. Chemosphere 37, 1571-1577.

Yamada, O., 1996. Structural Analyses of Coal and New Conversion Technologies. English Abstract from Journal of NIRE 5 (6) (Japanese).

Yaman, S., Karatepe, N., Küçükbayrak, S., 2000. Influence of wet oxidation on the surface area and the porosity of some lignites. Fuel 79, 1017-1022.

Yin, G., Liu, Z., Zhan, J., Ding, F., Yuan, N., 2002. Impacts of the surface charge property on protein adsorption on hydroxyapatite. Chemical Engineering Journal 87, 181-186.

Zawadski, J., 1988. Infrared studies of aromatic compounds adsorbed on the surface of carbon films. Carbon 26, 603-611. 